\title{
Effects of resistance exercise in prostate cancer patients: a meta-analysis
}

\author{
M. Keilani ${ }^{1}$ - T. Hasenoehrl ${ }^{1}$ - L. Baumann ${ }^{2} \cdot$ R. Ristl $^{2}$ - M. Schwarz ${ }^{1} \cdot$ M. Marhold $^{3}$ • \\ T. Sedghi Komandj ${ }^{1} \cdot$ R. Crevenna ${ }^{1}$
}

Received: 11 February 2017 / Accepted: 30 May 2017 /Published online: 10 June 2017

(C) The Author(s) 2017. This article is an open access publication

\begin{abstract}
Purpose The aim of the present meta-analysis was to quantify effects of resistance exercise (RE) on physical performance and function, body composition, health-related quality of life (HRQoL), and fatigue in patients with prostate cancer.

Methods Trial data were obtained from the databases PubMed, MEDLINE, EMBASE, SCOPUS, and the Cochrane Library as of inception to 31st of December 2016. Thirty-two trials with 1199 patients were included. Results that were measured by using the same assessment method in five or more of the original studies were pooled in a metaanalysis.

Results Pooled studies showed significant improvements of muscular strength in the upper and lower body $(95 \% \mathrm{CI}$ $[2.52,7.97] \mathrm{kg} ; p<0.001$ and $95 \%$ CI $[10.51,45.88] \mathrm{kg}$; $p=0.008$, respectively) after RE. Furthermore, significant improvements were seen for body composition (body fat percentage $95 \% \mathrm{CI}[-0.79,-0.53] \% ; p<0.001$; lean body mass $95 \%$ CI $[0.15,1.84] \% ; p=0.028$; trunk fat mass $95 \%$ CI $[-0.73,-0.08] \mathrm{kg} ; p=0.024)$. Additionally, the improvement of the $400-\mathrm{m}$ walk time was significant $(95 \%$ CI $[-21.55$, $-14.65] \mathrm{s} ; p<0.001)$. Concerning fatigue and HRQoL, there were not sufficient data for analysis.
\end{abstract}

R. Crevenna

richard.crevenna@meduniwien.ac.at

1 Department of Physical Medicine, Rehabilitation and Occupational Medicine, Medical University of Vienna, Comprehensive Cancer Center, Waehringer Guertel 18-20, 1090 Vienna, Austria

2 Section of Medical Statistics, CeMSIIS, Medical University of Vienna, Waehringer Guertel 18-20, 1090 Vienna, Austria

3 Department of Internal Medicine I/Oncology, Medical University of Vienna, Comprehensive Cancer Center, Waehringer Guertel 18-20, 1090 Vienna, Austria
Conclusions RE seems to be a promising approach in order to counteract loss of muscle mass, muscle strength, and physical performance in patients suffering from prostate cancer and its treatment-related side effects. RE should play part in interdisciplinary cancer rehabilitation and care of this patient group. Nevertheless, further research should investigate RE further to determine which protocols are the most pragmatic, yet yielding best patient outcomes.

Keywords Prostate cancer - Resistance exercise $\cdot$ Androgen deprivation therapy $\cdot$ Body composition $\cdot$ Muscular strength . Physical performance

\section{Introduction}

In 2012, 1.1 million men were diagnosed with prostate cancer (PCa) worldwide, accounting for $15 \%$ of all cancer diagnoses in men. Thus, $\mathrm{PCa}$ is the second most common cancer in men and the fifth leading cause for cancer in men. With an estimated 307,000 deaths, PCa represents $6.6 \%$ of total male cancer mortality [1]. In Austria, from 2012 to 2014, the 1- and 3-year survival rates were 95.3 and $92.7 \%$, respectively, the 5-year survival rate was $92.1 \%$ from 2007 to 2011 , and the 10-year survival rate was $91.2 \%$ from 2002 to 2006 [2], indicating excellent survival rates of prostate cancer patients (PCaPs). However, $\mathrm{PCa}$ and its treatment are related with considerable side effects, including muscular atrophy, weight changes, pain, and an overall decrease in health-related quality of life (HRQol) [3]. Side effects during prostate cancer treatment can cause serious health problems as well as a substantial limitation of HRQoL in patients suffering from the disease [4]. Depressive symptoms, impaired cognitive performance, sexual dysfunction, loss of libido, penile shortening, and gynecomastia are meaningful side effects that usually affect the 
Fig. 1 Flowchart of patient allocation and dropouts

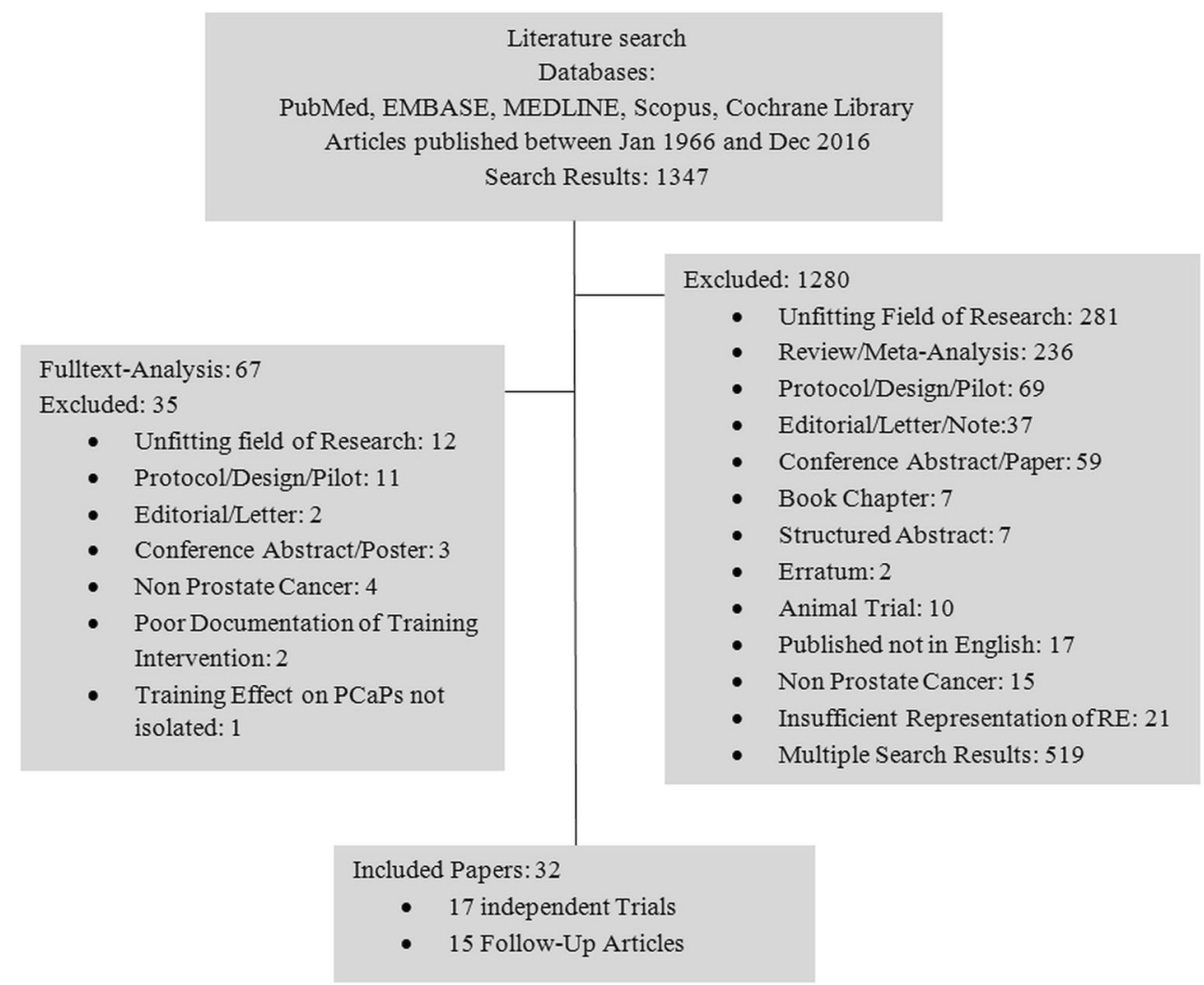

mental state and HRQoL of PCaPs [4-8]. These factors for mental distress might play a role in the development of increased risk of suicide in $\mathrm{PCaPs}[5,9]$. PCaPs undergoing androgen deprivation therapy (ADT) can additionally suffer from the symptoms of hot flushes, decreased physical activity, and detrimental changes of their body composition, which potentially leads to a deteriorated cardiovascular risk profile [7, 10-14]. Moreover, sex steroid deficiency induced by ADT leads to a decline in trabecular density and a decrease in bone mineral density (BMD), which correlates with fracture risk [15]. Furthermore, ADT is associated with an increased rate of fracture and fracture associated mortality [16, 17]. In a previously published systematic review, a qualitative overview of the meaningful effects of $\mathrm{RE}$ in the rehabilitation of PCa was performed [18]. However, the number of high- quality randomized controlled trials (RCTs) has increased substantially since then. Therefore, we decided to perform a quantitative analysis of the currently available data.

Treatment of prostate cancer includes surgery, radiation therapy, targeted therapy, and chemotherapy. Furthermore, ADT is part of the standard therapy for patients suffering from high-risk disease, defined as those cases with stage T3 and T4 tumors, a Gleason score of 8 to 10 and PSA levels higher than $20 \mathrm{ng} / \mathrm{mL}$, as well as locally advanced prostate cancer [3, 19]. ADT seems to be a valuable adjuvant to radiation therapy for high-risk prostate cancer [19]. Almost half of all PCaPs receive ADT at some point in their therapy [20, 21]. Long-term ADT is known to improve mortality [22-24], but comes at the cost of treatment-related morbidity [25]. PCaPs receiving ADT are susceptible to loss of muscle strength and muscle
Fig. 2 Funnel plot for reported mean differences in bench press/ chest press measurements
Bench Press/Chest Press

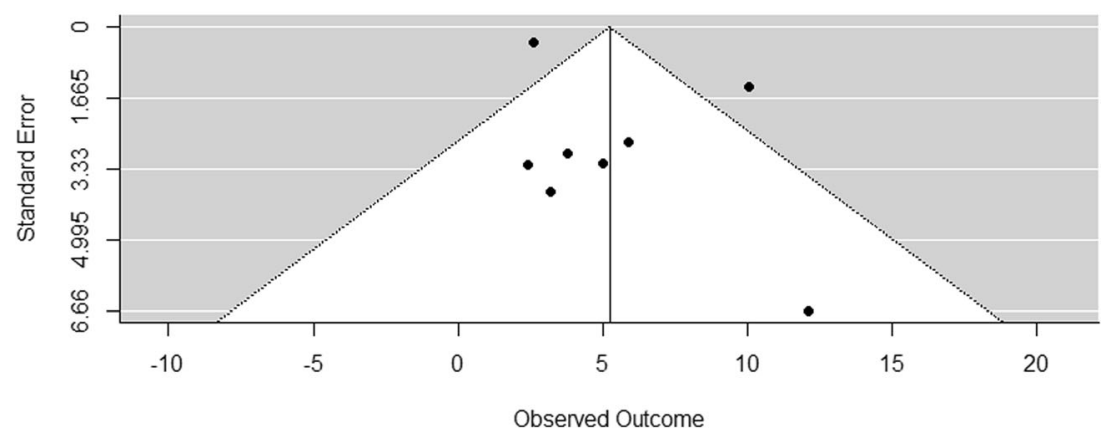


Fig. 3 Funnel plot for reported mean differences in leg press measurements

Fig. 4 Funnel plot for reported mean differences in body fat percentage

\section{Leg Press}

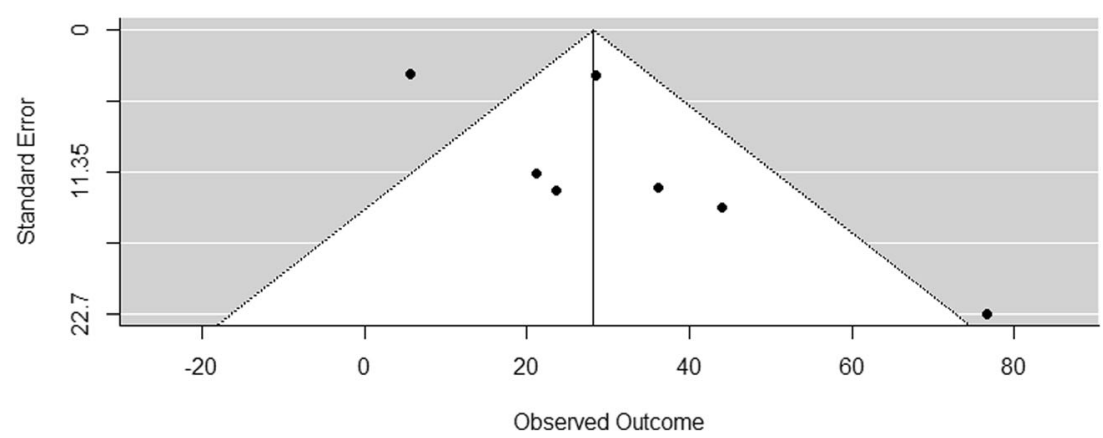

Body Fat

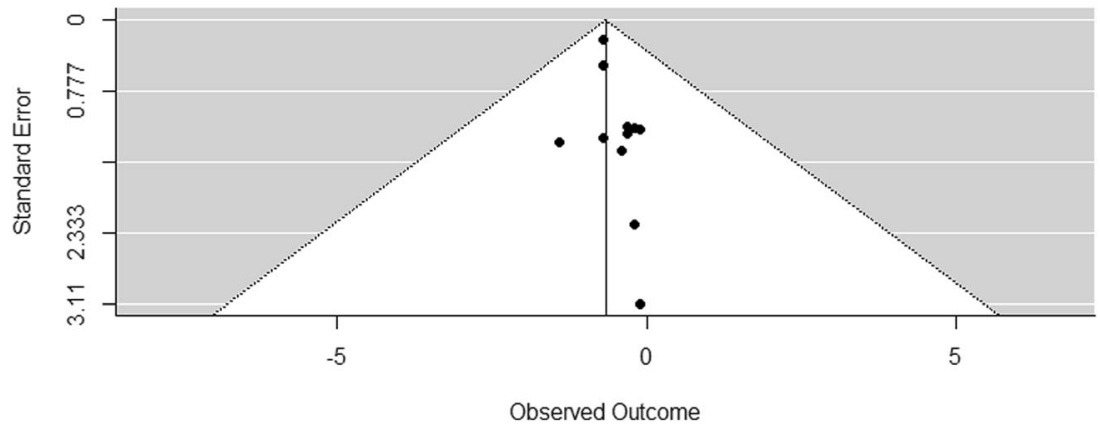

mass, as well as increase of fat mass [12-14]. Further side effects of ADT are alterations in lipolysis profile [26, 27] and insulin metabolism $[14,27,28]$ as well as increased arterial stiffness $[27,28]$. These changes are accompanied with an increased risk for developing cardiovascular disease [27, 29-31], diabetes mellitus type II [29], and osteoporosis [13, 32]. ADT is related to earlier onset of serious myocardial infarctions, especially in PCaPs older than 65 years of age [33]. Therefore, lifestyle changing interventions like dietary adjustments and exercise were recommended to mitigate cardiovascular risk [30]. The negative changes of body composition that are particularly associated with ADT and their visible effect like muscle loss, gynecomastia, and female pattern weight gain are perceived as emasculating and hence associated with psychosocial morbidity in PCaPs [9]. Consequently, preservation of body composition alone is already considered a positive outcome in PCaPs. Resistance exercise (RE) has shown beneficial effects not just in the general public, but in specific patient populations such as patients suffering from metabolic syndrome, chronic obstructive pulmonary disease, and cancer [34-36]. As the loss of muscle mass and increase of visceral fat mass may be a key factor in the development of cardiovascular disease [37], RE, causing initiation of muscle hypertrophy, might be the medical training therapy of choice to effectively combat adverse body composition changes. Aerobic exercise (AE) might be a potent exercise modality to decrease visceral fat mass and to counteract an increased cardiovascular risk profile. In $\mathrm{PCa}$, however, $\mathrm{AE}$ does not target the basic physiology of the problem, which is loss of muscle mass. Moreover, RE may indirectly have a beneficial
Fig. 5 Funnel plot for reported mean differences in whole body fat mass
Whole Body Fat Mass

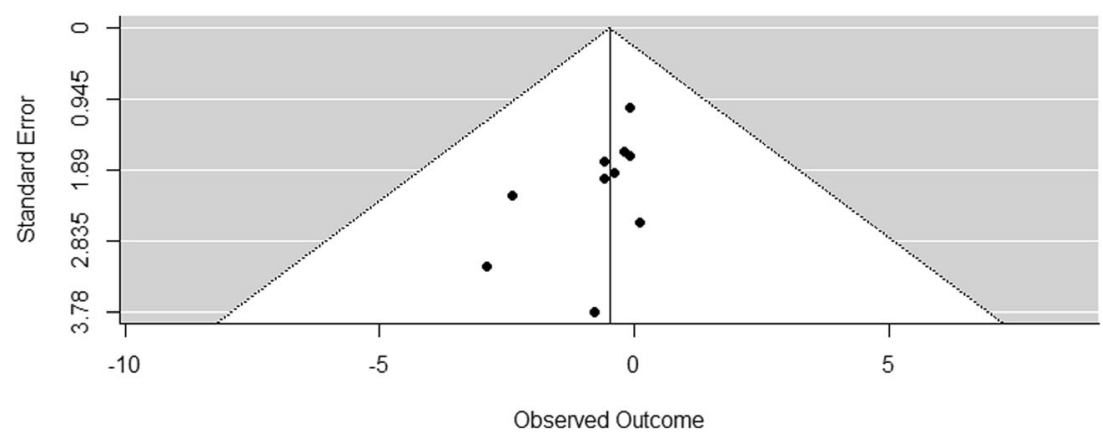


Fig. 6 Funnel plot for reported mean differences in whole body lean mass

Fig. 7 Funnel plot for reported mean differences in trunk fat
Whole Body Lean Mass

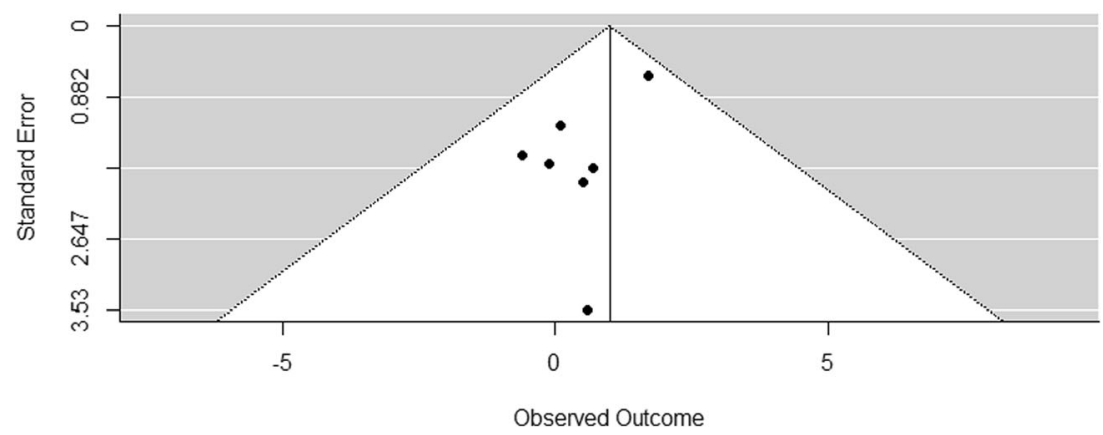

Trunk Fat Mass

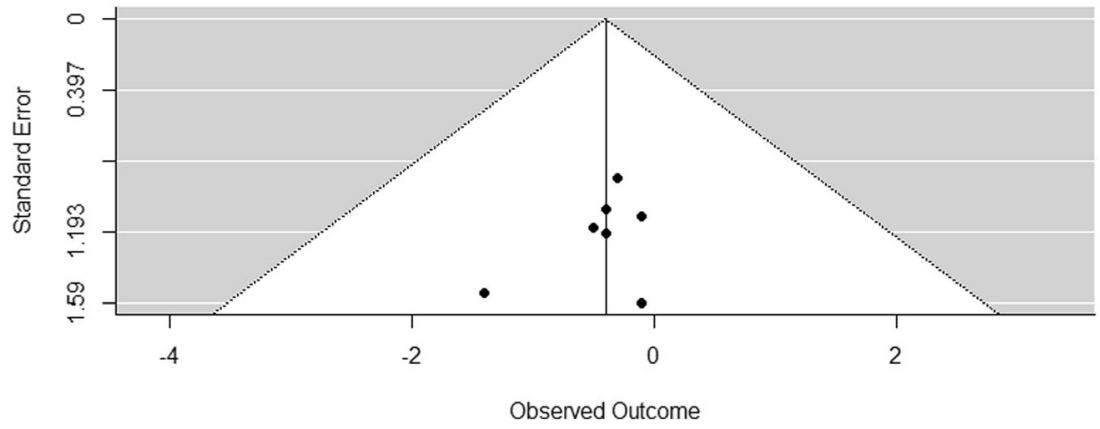

effect on visceral fat mass via an upregulation of adipose tissue lipolysis, as mediated through adiponectin [38]. RE seems to be a safe, feasible, and effective rehabilitation tool for PCaPs undergoing ADT [18]. To our knowledge, no metaanalysis has recently investigated the effectiveness of RE in PCaPs. We hypothesize that RE has significant beneficial effects on muscle strength, physical performance and function, body composition, HRQoL, and fatigue in PCaPs. The aim of this meta-analysis was to quantify these effects.

\section{Methods}

A systematic literature research for RE intervention trials with PCaPs published in English language between January 1966 and 31st of December 2016 was conducted by using the scientific medical databases PubMed, MEDLINE, EMBASE, SCOPUS, and Cochrane Library. Further, reference lists of relevant publications were searched for additional studies. The search strategy included the search terms "resistance exercise," "resistance training," "strength training," "prostate cancer," "androgen deprivation therapy" and "androgen suppression therapy," and their possible variations. One thousand three hundred and forty-seven articles were found and screened for eligibility by title and abstract. One thousand two hundred and eighty studies had to be excluded for not meeting inclusion criteria [unsuitable type of study (review, study protocol, pilot studies, conference abstracts, etc.), insufficient representation of $\mathrm{RE}$ in the intervention branch, inapplicable type of cancer (non-PCa), multiple search results]
Fig. 8 Funnel plot for reported mean differences in 400-m walking time 400m Walk

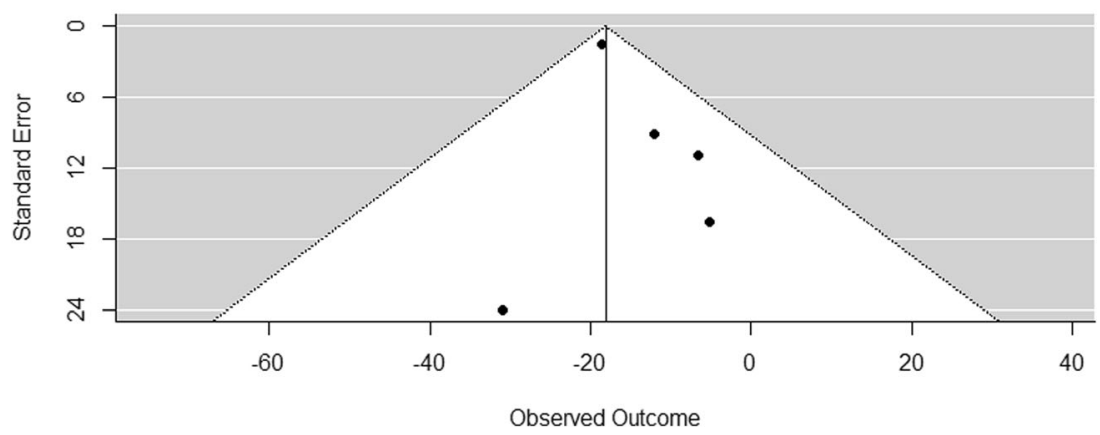




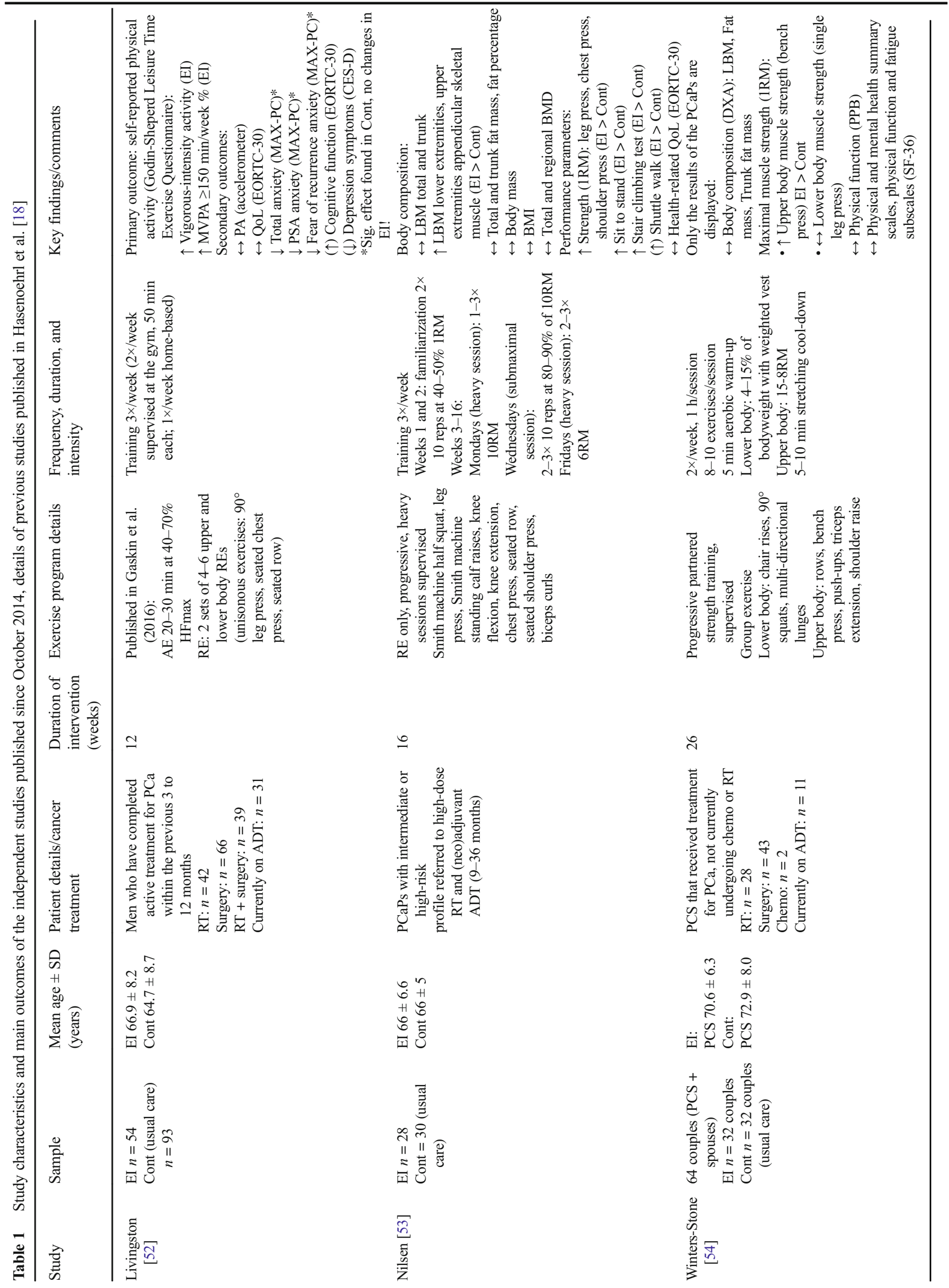




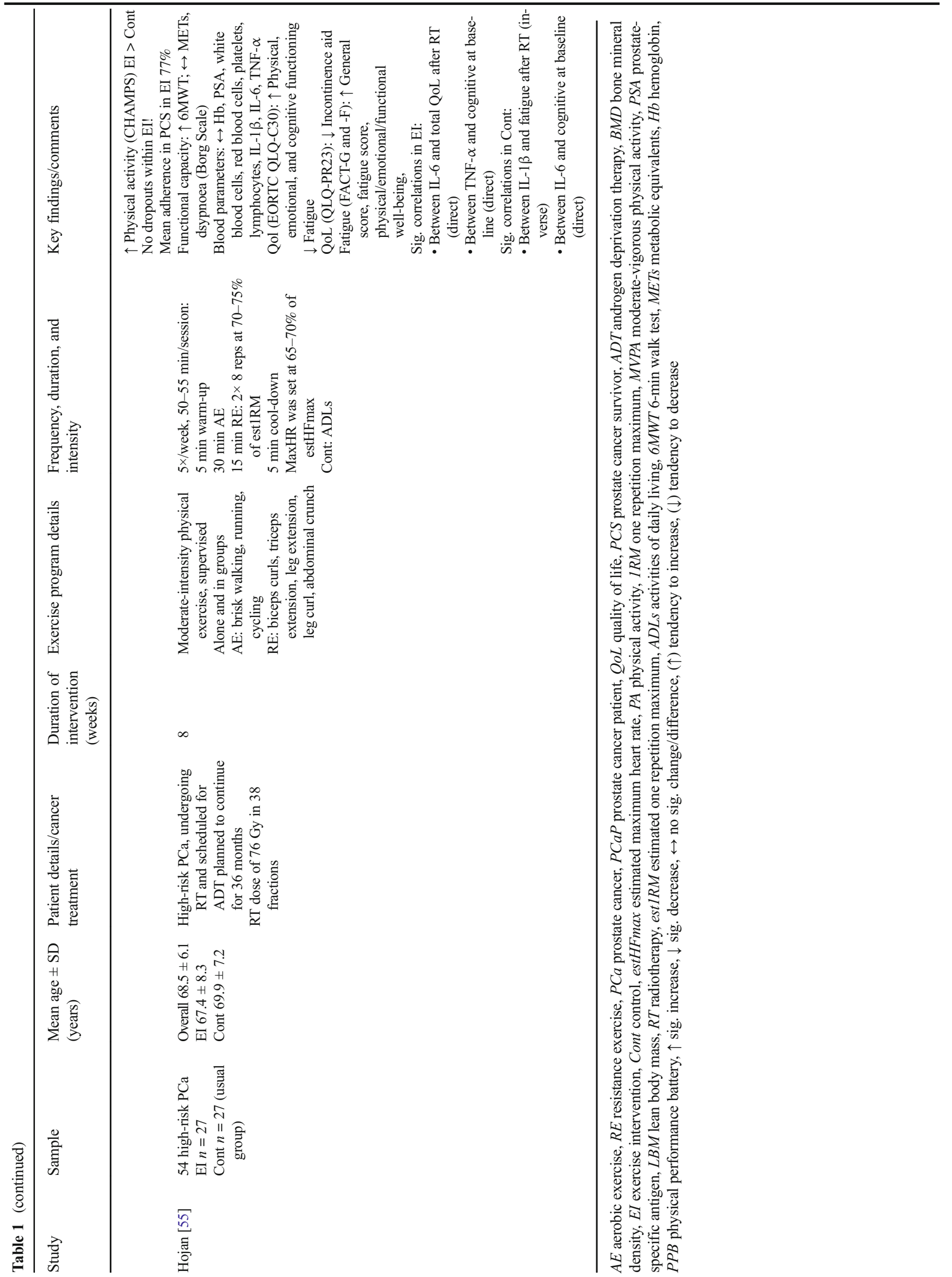


Table 2 Results of the additional articles published since October 2014, details of previous studies published in Hasenoehrl et al. [18]

\begin{tabular}{ll}
\hline Additional article & Expansion \\
\hline $\begin{array}{l}\text { Gaskin [64] } \\
\text { Additional article of } \\
\text { Livingston [52] }\end{array}$ & Additional results \\
& \\
& \\
& \\
& \\
Nilsen [65] & \\
Additional article of & Additional results \\
Nilsen [53] & outcomes \\
& (biopsies) \\
& EI: $n=12$ \\
& Cont: $n=11$
\end{tabular}

Nilsen [66]

Additional article of Nilsen [53]

Buffart [67]

Additional article of Galvao [45]

Additional results

Muscle cellular stress

EI: $n=16$

Moderator and

mediator analysis
Results

- $\uparrow$ Aerobic fitness (6-min walk test)

- $\uparrow$ Upper body maximal strength (1RM, $90^{\circ}$ leg press)

- $\uparrow$ Lower body maximal strength (1RM, seated chest press)

- $\uparrow$ Lower body muscular endurance (sit to stand test)

- $\uparrow$ Balance (functional reach test)

• $\leftrightarrow$ BMI

- $\leftrightarrow$ Girth measurements (chest, waist, hips, upper arm, mid-thigh)

- $\leftrightarrow$ Resting heart rate

- $\leftrightarrow$ Blood pressure

Muscle fiber CSA

- $(\uparrow)$ Within group difference (EI)

- $\leftrightarrow$ Within group difference (Cont)

- $\uparrow$ Between group difference (EI > Cont) (larger effect in type II fibers)

Number of myonuclei

- $\uparrow$ Within group difference (EI)

- $\leftrightarrow$ Within group difference (Cont)

- $(\uparrow)$ Between group difference (EI > Cont)

Myonuclear domain

- $\leftrightarrow$ EI and Cont within group difference

- $\leftrightarrow$ EI vs. Cont between group difference

Myonuclei per muscle fiber

- $\uparrow$ EI type I fibers

Muscle fiber CSA/myonuclei

$\bullet \downarrow$ EI type I fibers

Number of satellite cells

- $\leftrightarrow$ EI and Cont, EI vs. Cont

$\leftrightarrow$ Androgen receptor and myostatin

Muscle strength (knee extensor 1RM)

- $\uparrow$ Within group difference (EI)

- $\leftrightarrow$ Within group difference (Cont)

- $\uparrow$ Between group difference (EI > Cont)

Mitochondrial proteins, between group effects:

Cont: $n=15$

- $\leftrightarrow$ Cytochrome c oxidase subunit IV (COXIV)

$\bullet \leftrightarrow$ HSP60

Mitochondrial proteins, within group effects:

- $(\downarrow)$ Citrate synthase in Cont

Indicators of muscle cellular stress, between group effects:

• $\leftrightarrow$ HSP70

- $\leftrightarrow$ Alpha-B crystallin

$\bullet \leftrightarrow \operatorname{HSP} 27$

- $\leftrightarrow$ Free ubiquitin

- $\leftrightarrow$ Total ubiquinated proteins

Indicators of muscle cellular stress, within group effects:

$\bullet \downarrow$ HSP70 in EI Moderators:

- Marital status moderated the effect of EI on global QoL in favor of married patients (no difference in attendance). 
Table 2 (continued)

Gilbert [68]

Additional article of Bourke [40]
Lyons [69]

Additional article of Winters-Stone [54]

Winters-Stone [70]

Additional article of Winters-Stone [51]
Additional results

Endothelial function

Additional results

Levels of physical intimacy

Additional results

Body composition, blood biomarkers
Results

- Time since diagnosis moderated the effect of EI on global QoL and physical, emotional, cognitive, and social function with a smaller effect in patients who started exercising later after diagnosis compared with those who started sooner (no association with attendance).

- Significant moderation effect of presence of comorbidity on cognitive function with a larger effect in patients with comorbidities.

- Borderline moderation effect of biphosphonate use on physical, role, and emotional function in favor of patients who previously used biphosphonates (no difference in attendance).

Mediators and associations:

- Chair rise time significantly mediated effect of EI on global QoL and physical and social function.

- Chair rise test improvements associated with improvements in global QoL and physical and social function.

- Self-reported PA increases associated with improvements in global QoL.

- Fatigue reductions associated with improvements in global QoL and physical, role, emotional, and social function.

- Distress reductions associated with improvements in global QoL and physical and role function.

- Falls self-efficacy improvements associated with improvements in global QoL and physical, role, and social function.

- No significant mediating effects on health-related QoL outcomes for aerobic fitness, physical activity, fatigue, distress, or falls self-efficacy.

Results from a subset of 50 subjects from the original trial (25 $\mathrm{EI}+25$ Cont):

Vascular assessments/endothelial function:

- $\uparrow$ FMD at 12 weeks

- $(\downarrow)$ Diastolic blood pressure

- $\leftrightarrow$ Systolic blood pressure

Body composition (BiA):

- $\uparrow$ Skeletal muscle mass at 12 weeks

- $\leftrightarrow$ Lipid profile

Blood markers:

- $\uparrow$ SHBG

- $\leftrightarrow$ Total testosterone, free androgen index, PSA

Exercise tolerance:

- $\uparrow$ Treadmill walk time at 12 and 24 weeks

Exercise and dietary behavior:

- $\uparrow$ Exercise behavior (Godin LSI) at 12 weeks

- $\leftrightarrow$ Dietary behavior

Engagement in affectionate and sexual behaviors

- Engagement in affectionate behaviors: $\uparrow$ wives and $\leftrightarrow$ husbands in the EI group compared to Cont

- Engagement in sexual behaviors: $\leftrightarrow$ husbands and wives

Body composition and blood biomarkers

- $\downarrow$ Total fat

- $(\downarrow)$ Percent body fat 
Table 2 (continued)

\begin{tabular}{ll}
\hline Additional article & Results \\
\hline Moderation and & $\bullet(\downarrow)$ Trunk fat \\
mediation & $\bullet \leftrightarrow$ Lean mass \\
analysis & $\bullet \leftrightarrow$ Insulin \\
& $\bullet \leftrightarrow$ IGF-1 \\
& $\bullet \leftrightarrow$ SHBG \\
& $\bullet(\uparrow)$ Physical activity energy expenditure \\
& Moderation and mediation analysis \\
& $\bullet$ Age moderates the insulin response to exercise (insulin \\
& reductions were smaller with increasing age) \\
& - Sig. indirect effect of loss of total fat mass and loss of trunk \\
& fat mass on group differences in insulin from baseline to \\
& 12 months
\end{tabular}

Cont control group, BMI body mass index, $E I$ exercise intervention, $Q O L$ quality of life, $P S A$ prostate-specific antigen, $I G F-1$ insulin-like growth factor $1, I R M$ one repetition maximum, $H S P$ heat shock protein, $F M D$ flowmediated dilatation, BiA bioelectrical impedance analysis, $L S I$ Leisure Score Index, SHBG sex hormone-binding globulin, $\uparrow$ sig. increase, $\downarrow$ sig. decrease, $\leftrightarrow$ no sig. change/difference, $(\uparrow)$ tendency to increase, $(\downarrow)$ tendency to decrease

which left 67 for full text analysis. Of those, 32 articles finally met inclusion criteria of being relevant RE intervention trials with RE either as the sole exercise intervention or in combination with any other exercise modality in PCaPs [39-70]. Seventeen of those 32 studies were identified as independent studies [39-55], which published the primary results of a specific population sample for the first time. Those studies included 1199 patients of which 580 were allocated to a RE intervention group. Most of those studies included only PCaPs on current or previous ADT [39-47, 49, 51, 53, 55], some included both PCaPs on ADT and non-ADT [50, $52,54]$ and one excluded PCaPs with adjuvant or neoadjuvant therapy after radical prostatectomy [48]. In the other 15 trials, additional outcomes or analyses of the former studies were published [56-70]. This distinction was particularly important to prevent multiple representations of data of the same sample in our meta-analysis. Additionally, the content of one erratum [41] was taken into account. An overview over the selection process is presented in Fig. 1. The process of systematic literature review as well as selection of suitable articles was conducted independently by two experienced researchers following the PRISMA reporting guidelines for systematic reviews and meta-analyses. For each study, results regarding body composition, strength, functional and cardiovascular performance, as well as HRQoL and fatigue were reviewed and used for meta-analysis.

\section{Statistical analysis}

All outcome variables measured with the same assessment method in five or more of the original studies were subject to meta-analyses. Outcome variables reported in less than five studies were not considered for meta-analysis as the results are considered unreliable when a small number of heterogeneous studies are used [71]. For all variables, the relevant effect measure was the difference in means between the respective
Fig. 9 Mean differences in bench press/chest press strength measurements in the original studies and summarized estimate from the random effects meta-analysis model. Positive values indicate increases in strength and therefore a beneficial effect of RE. Intervals are $95 \%$ confidence intervals
Bench Press/Chest Press

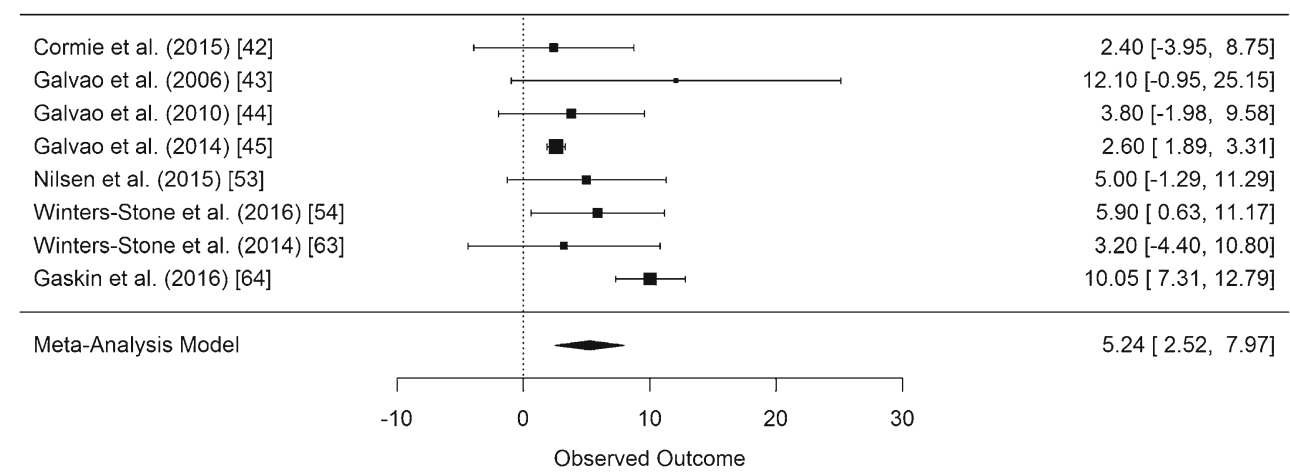


Fig. 10 Mean differences in leg press strength measurements in the original studies and summarized estimate from the random effects meta-analysis model. Positive values indicate increases in strength and therefore a beneficial effect of RE. Intervals are $95 \%$ confidence intervals
Leg Press

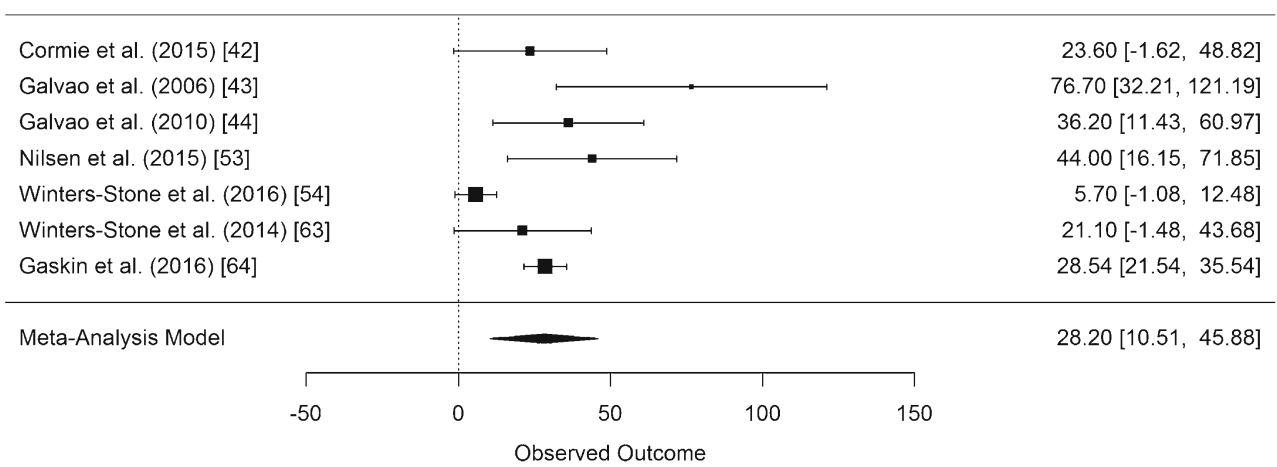

baseline and post-intervention values. The standard deviation of the differences was reported in one study [64], while standard deviations of baseline and postintervention values were reported in all other studies. For these studies, the (conservative) assumption of a zero correlation between pre- and post-intervention values was made when calculating the standard error of the difference in means.

A weighted random effects meta-analysis model was fitted for each outcome variable using the DerSimonianLaird approach. Confidence intervals for the summary effect measure and $p$ values for according tests of no effect were calculated using Knapp and Hartung adjustments. To investigate the possibility of publication bias, funnel plots were inspected (Figs. 2, 3, 4, 5, 6, 7, and $8)$. In the funnel plots, triangular areas are displayed that are expected to contain $95 \%$ of the observed values given there is no heterogeneity between studies. Under the realistic assumption of heterogeneity, a larger fraction of studies may be found outside these areas. Statistical analyses were performed using the library metafor [72] in the statistical computing environment R 3.1.

\section{Results}

Descriptive characteristics of the included studies that were published since October 2014 are presented in Tables 1 and 2. Details of studies that were published previously are presented elsewhere [18].

\section{Risk of bias analysis}

The funnel plot of lower body muscle strength (leg press) (Fig. 3) was suspicious, but the variable remained in the analysis due to reasons addressed in the discussion section. Funnel plots of the other outcome variables showed no sign of publication bias.

\section{Muscle strength}

The results of bench press/chest press 1RM measurements were pooled from eight studies [42-45, 53, 54, 63, 64]. The difference in means for measurements was found to be significantly greater than zero, with an estimated increase of $5.24 \mathrm{~kg}$ (CI $[2.52,7.97] ; p<0.001)$. The results are presented in Fig. 9. Eight studies examined effects of RE on lower
Fig. 11 Mean differences in body fat percentage in the original studies and summarized estimate from the random effects metaanalysis model. Positive values indicate increases in strength and therefore a beneficial effect of RE. Intervals are $95 \%$ confidence intervals
Body Fat

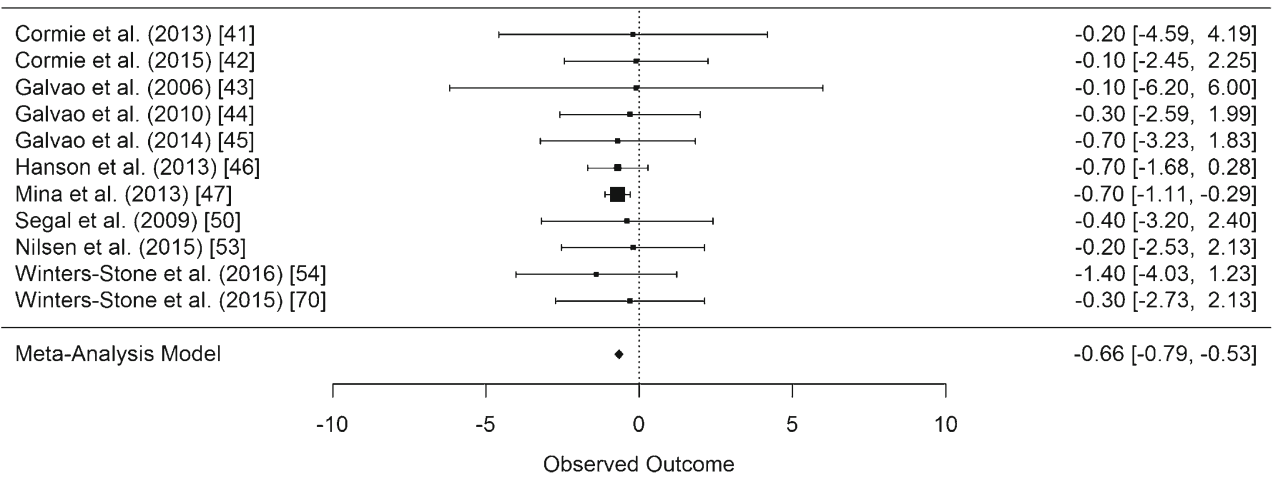


Fig. 12 Mean differences in whole body fat mass in the original studies and summarized estimate from the random effects meta-analysis model. Positive values indicate increases in strength and therefore a beneficial effect of RE. Intervals are $95 \%$ confidence intervals
Whole Body Fat Mass

\begin{tabular}{lll}
\hline Cormie et al. (2013) [41] & \\
Cormie et al. (2015) [42] \\
Galvao et al. (2006) [43] \\
Galvao et al. (2010) [44] \\
Galvao et al. (2014) [45] \\
Hanson et al. (2013) [46] \\
Nilsen et al. (2015) [53] \\
Winters-Stone et al. (2016) [54] \\
Gilbert et al. (2016) [68] \\
Winters-Stone et al. (2015) [70] \\
\hline Meta-Analysis Model
\end{tabular}

body strength by assessing the 1RM leg press [42-44, $46,53,54,63,64]$. The pooled results of seven studies $[42-44,53,54,63,64]$ showed that the difference in means for leg press was significantly greater than zero, with an estimated increase of $28.20 \mathrm{~kg}$ (CI [10.51, 45.88]; $p=0.008$ ) (Fig. 10). In both strength measurements, the results of Hanson et al. (2013) had to be disregarded for meta-analysis because mean values were not presented [46].

\section{Body composition}

Body fat percentage was assessed in 11 studies [41-47, $50,53,54,70]$, all but one assessed with dual x-ray absorptiometry (DXA) [47]. The difference in means for body fat percentage was significantly smaller than zero, with an estimated decrease of $0.66 \%$ (CI $[-0.79$, $-0.53] ; p<0.001$, Fig. 11).

Whole body fat mass was assessed in ten of the included studies [41-46, 53, 54, 68, 70]. The difference in means for whole body fat mass was not significantly different from zero but showed a tendency to decrease (CI [-1.04, 0.06] kg; $p=0.075$, Fig. 12).

The results of whole body lean mass was pooled from seven studies that all used DXA [41, 42, 44-46, 53, 54].
The difference in means for whole body lean mass was significantly greater than zero, with an estimated increase of $1 \mathrm{~kg}$ (CI [0.15, 1.84]; $p=0.028$, Fig. 13).

Trunk fat mass was assessed with DXA in seven studies $[41,42,44,45,53,54,70]$. The difference in means for trunk fat mass was significantly smaller than zero, with an estimated decrease of $0.4 \mathrm{~kg}$ (CI [-0.73, $-0.08] ; p=0.024$, Fig. 14).

\section{Physical performance}

As measurement of cardiovascular fitness, six studies performed a 400-m walk test [41-46]. As Hanson [46] did not present mean values, the results of the remaining five studies [41-45] were pooled for the meta-analysis. The difference in means for the 400-m walk is significantly smaller than zero, with an estimated decrease of $18.10 \mathrm{~s}$ (CI [-21.55, -14.65]; $p<0.001$, Fig. 15).

\section{Functional performance, HRQoL, fatigue}

Functional performance was assessed in several studies with different outcome variables. Quoted in excerpts, the 6-m walk was assessed in five studies [42-44, 46, 73], repeated chair rise [42-45] and sit-to-stand test [39, 46, 53, 64] in four
Fig. 13 Mean differences in whole body lean mass in the original studies and summarized estimate from the random effects meta-analysis model. Positive values indicate increases in strength and therefore a beneficial effect of RE. Intervals are $95 \%$ confidence intervals
Whole Body Lean Mass

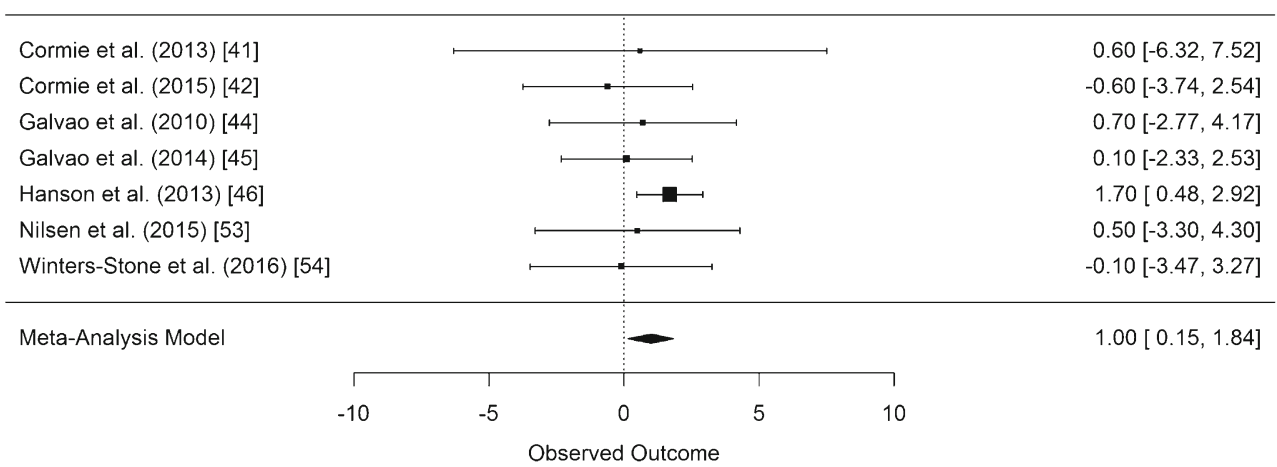


Fig. 14 Mean differences in trunk fat mass in the original studies and summarized estimate from the random effects metaanalysis model. Positive values indicate increases in strength and therefore a beneficial effect of RE. Intervals are $95 \%$ confidence intervals
Trunk Fat Mass

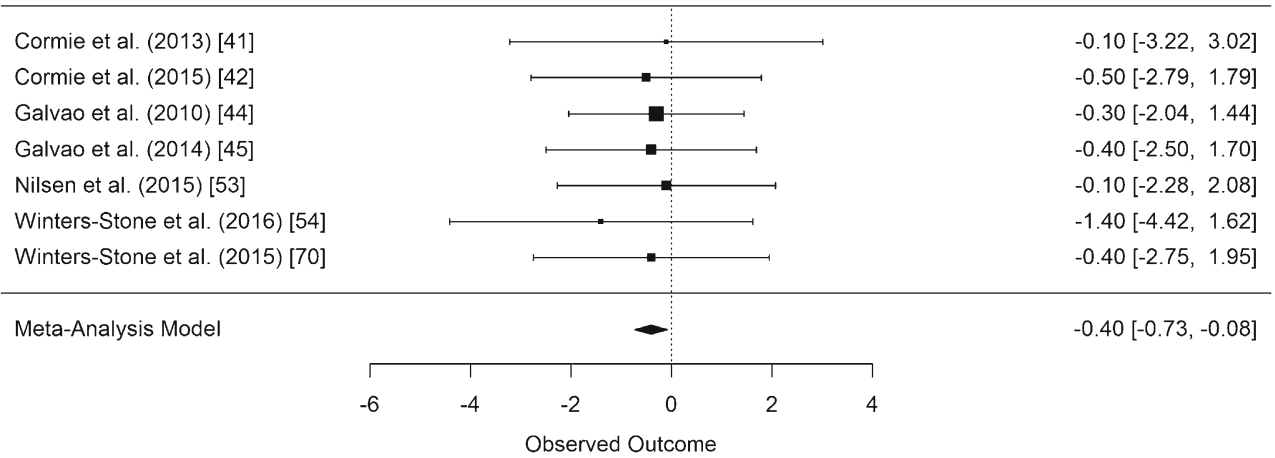

studies, and Timed Up and Go test in two studies [41, 46]. Sufficient data existed for the 400-m walk tests only, which were subject to meta-analysis.

HRQol was assessed in 12 studies, but the assessment methods were very heterogeneous; therefore, there was no sufficient data for meta-analysis [39-42, 44-47, 49, 50, 53, 54].

Fatigue was assessed in nine studies [39-42, 46, 47, 49, 50, 53]. Five studies assessed fatigue with the FACT-F [39, 40, $47,49,50]$, but only four presented sufficient data for the meta-analysis. Therefore, meta-analysis for fatigue was not feasible.

\section{Discussion}

The results of the present meta-analysis showed that there are several beneficial effects for PCaPs associated with RE. Both lower and upper body muscle strength and cardiovascular fitness as well as measures of body composition increased significantly.

Regarding body composition, the results of this metaanalysis showed a significant decrease of whole body fat percentage and trunk fat, as well as a significant increase of whole body lean mass in PCaPs who performed RE. This is of particular interest, since preserving body composition itself should be considered a positive outcome in RE for PCaPs.

Just like suffering from cancer and various other treatment modalities (e.g., radiation therapy and chemotherapy), ADT is associated with reduced functional performance, impaired dynamic balance, and decreases in strength. These factors affect risk of falls and successful performance of activities of daily living (ADL) $[32,74]$. The preservation of physical performance levels as shown in this meta-analysis should be seen as a further positive clinical outcome of RE in PCaPs. In accordance to this finding, quantitative analysis of currently available data showed that physical performance parameters significantly increased with RE. Further, PCaPs significantly improved upper and lower body strength while performing RE which we argue could decrease fall risk and increase ADL performance. It has been noted that results of 400-m walk time tests-where participants walk laps in a marked corridor aiming to complete the full distance as quickly as possiblehave to be treated with caution [75]. Although the metaanalysis showed a significant decrease of $18.10 \mathrm{~s}$, Kwon et al. (2009) described a minimally meaningful change of 20-30 s [76]. Their study, however, analyzed sedentary, elderly patients, and it is possible that smaller changes might prove to be clinically relevant for larger PCaPs cohorts. Moreover, physical performance is an important factor for $\mathrm{PCaPs}$ to
Fig. 15 Mean differences in 400$\mathrm{m}$ walking time in the original studies and summarized estimate from the random effects metaanalysis model. Positive values indicate increases in strength and therefore a beneficial effect of RE. Intervals are $95 \%$ confidence intervals 400m Walk

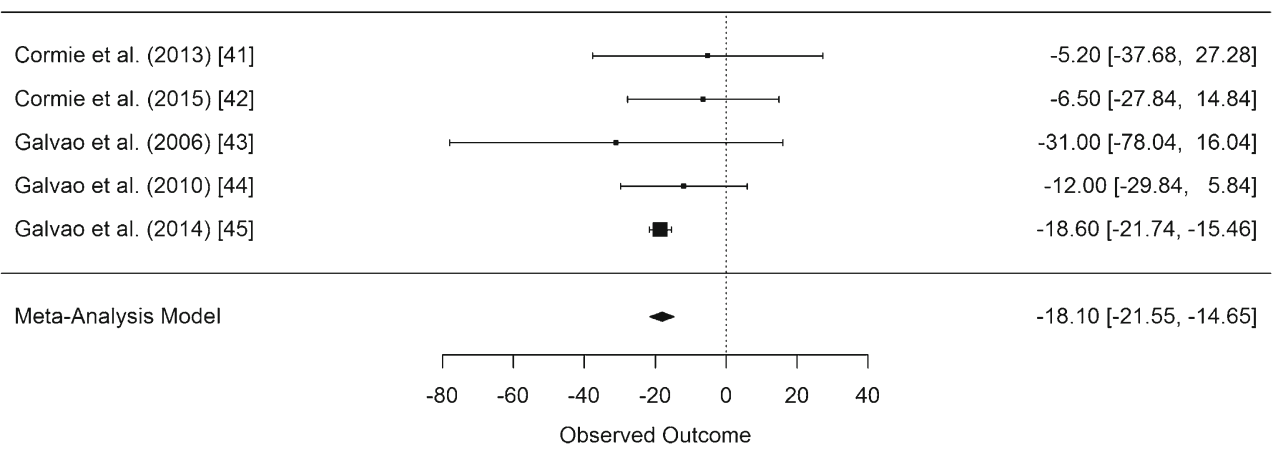


maintain HRQoL [77-80]. Therefore, an increase in physical performance seems to be directly related to the patients' ability to at least maintain if not to improve HRQoL. Unfortunately, as already described in the methods section, the available data regarding HRQoL was insufficient for meta-analysis because too many different assessment methods (FACT-P, QLQ-PR25, PORPUS, EORTC-C30, SF-36) were used within relevant studies. This heterogeneity among studies concerning assessment methods can be seen as a limitation of the present metaanalysis, and greater effort for international consensuses regarding HRQoL assessment is dearly needed to facilitate research in this field. Furthermore, although RE was performed in all studies included, heterogeneity in training methods still existed to a certain extent between interventions. Most of the studies that were included performed at moderate to high intensities in the range of the 15-6 repetition maximum (about $60-85 \%$ of 1RM) [40-45, 47, 49, 53, 54, 63, 64, 70]. In two studies, light to moderate loads were used for exercise (bodyweight, 50-70\% of 1RM) [39, 48]. The participants of the study by Hanson et al. performed RE at very high intensity (5RM) [46]. Their results for body fat percentage and body fat mass did not differ substantially from the other studies that were included in this meta-analysis (Figs. 11 and 12), but their results for whole body lean mass were the only ones reaching statistical significance (Fig. 13) [30]. This could have affected the pooled results of the meta-analysis of effects of RE on whole body lean mass towards a positive outcome. Nevertheless, we decided to include these results because they seem to provide an indication that high-intensity RE might be superior to moderate- to high-intensity RE if muscle hypertrophy is seen as the primary goal of exercise in PCaPs. Another limitation of this meta-analysis is that due to the small number of high-quality RCTs, both studies conducting RE as the sole intervention and studies conducting RE in combination with other exercise interventions were included. Future meta-analyses, able to select more studies including higher numbers of patients receiving solely RE or RE in combination exercise, are recommended to evaluate potentially different outcomes in PCaPs. However, as a specific training stimulus can be attributed to a functional outcome, we do not perceive the incorporation of combined RE interventions in our analyses as a major problem. As previously reported, RE is primarily associated with an increase in strength and lean body mass, whereas AE is primarily associated with adaptations of the cardiovascular system. Therefore, the bench press outcome of a combined training intervention study should not be affected by the AE intervention (e.g., cycling) but the RE intervention only. For a more complex understanding of exercise interventions in $\mathrm{PCaPs}$, future meta-analyses should aim to isolate the results of homebased exercise trials from those of trials with supervised training sessions, as $\mathrm{AE}$ in a home-based environment seems to be easier to perform than RE, which in contrast seems to be more difficult to perform without supervision [47].
In order to check for publication bias, funnel plots were inspected (Figs. 2, 3, 4, 5, 6, 7, and 8). On the one side, leg press performance was untypically low in the study by Winters-Stone et al. (2016) [38]. On the other side, the respective results were untypically high and unsteady in the trial by Galvao et al. (2006) [27] (Fig. 3). This difference might be due to different exercises and assessment methodologies used in these studies. In the study of Winters-Stone et al. (2016), RE for the lower body was performed with bodyweight and weighted vests [38]. From the sensorimotor perspective, this kind of RE has its advantages over machine-based RE. However, it might be limited regarding the development of sheer leg strength, especially when the participants are elderly PCaPs receiving cancer treatment and when strength outcome is measured with a standard 1RM test on the leg press. Galvao et al. (2006) [27], on the other hand, who reported very high outcomes, did not only assess 1RM but also measured muscle endurance. Their participants performed the maximal number of repetitions at $70 \%$ of their 1RM and, in contrast to the participants of the other studies, might therefore have had a learning effect when performing at complete exhaustion, which might be a decisive factor for 1RM performance [81]. The seeming deviation of these studies might thus be rather due to study heterogeneity, which was accounted for in the meta-analysis, and not due to publication bias.

A prevalent shortcoming in all of the included studies was the lack of blinding of the participants. This notion can be explained by the nature of randomized controlled exercise intervention studies, where blinding is not feasible.

\section{Conclusion}

In the present meta-analysis, we were able to confirm that RE is a potent approach in counteracting increase of body fat as well as loss of muscle mass, muscle strength, and physical performance in patients suffering from prostate cancer. RE should be an important part in multidisciplinary and interdisciplinary cancer rehabilitation of this patient group as it seems to have notable potential to reduce not only treatment-related side effects but also detrimental psychosocial health issues [9, 18]. Many PCaPs are undergoing long-term ADT [82], while substantial ADT side effects are already measurable after 3 months of treatment [83]. Therefore, implementation of $\mathrm{RE}$ as an early countermeasure as well as within a long-term rehabilitation process of $\mathrm{PCa}$ is essential in optimal supportive care of PCaPs. Nevertheless, further and larger studies examining different protocols of RE and their effectiveness at different treatment and disease stages should be key components of future research in this field.

Acknowledgements Open access funding provided by Medical University of Vienna. 


\section{Compliance with ethical standards}

Conflict of interest The authors declare that they have no conflict of interest.

Open Access This article is distributed under the terms of the Creative Commons Attribution-NonCommercial 4.0 International License (http:// creativecommons.org/licenses/by-nc/4.0/), which permits any noncommercial use, distribution, and reproduction in any medium, provided you give appropriate credit to the original author(s) and the source, provide a link to the Creative Commons license, and indicate if changes were made.

\section{References}

1. Ferlay J, Soerjomataram I, Dikshit R, Eser S, Mathers C, Rebelo M, Parkin DM, Forman D, Bray F (2015) Cancer incidence and mortality worldwide: sources, methods and major patterns in GLOBOCAN 2012. Int J Cancer 136:E359-E386. doi:10.1002/ ijc. 29210

2. Statistik Austria (2016) Prostata (C61) - Relative Überlebensraten in Österreich nach Geschlecht (1987-2014). 2016

3. Attard G, Parker C, Eeles RA, Schroder F, Tomlins SA, Tannock I, Drake CG, de Bono JS (2016) Prostate cancer. Lancet 387:70-82. doi:10.1016/S0140-6736(14)61947-4

4. Rhee H, Gunter JH, Heathcote P, Ho K, Stricker P, Corcoran NM, Nelson CC (2015) Adverse effects of androgen-deprivation therapy in prostate cancer and their management. BJU Int 115:3-13. doi:10. 1111/bju. 12964

5. Llorente MD, Burke M, Gregory GR, Bosworth HB, Grambow SC, Horner RD, Golden A, Olsen EJ (2005) Prostate cancer: a significant risk factor for late-life suicide. Am J Geriatr Psychiatry 13: 195-201. doi:10.1176/appi.ajgp.13.3.195

6. Green HJ, Pakenham KI, Headley BC, Yaxley J, Nicol DL, Mactaggart PN, Swanson C, Watson RB, Gardiner RA (2002) Altered cognitive function in men treated for prostate cancer with luteinizing hormone-releasing hormone analogues and cyproterone acetate: a randomized controlled trial. BJU Int 90:427-432. doi:10. 1046/j.1464-410X.2002.02917.x

7. Walker LM, Tran S, Robinson JW (2013) Luteinizing hormonereleasing hormone agonists: a quick reference for prevalence rates of potential adverse effects. Clin Genitourin Cancer 11:375-384. doi:10.1016/j.clgc.2013.05.004

8. Green HJ, Pakenham KI, Headley BC, Yaxley J, Nicol DL, Mactaggart PN, Swanson CE, Watson RB, Gardiner RA (2004) Quality of life compared during pharmacological treatments and clinical monitoring for non-localized prostate cancer: a randomized controlled trial. BJU Int 93:975-979. doi:10.1111/j.1464-410X. 2004.04763.x

9. Cormie P, Oliffe JL, Wootten AC, Galvão DA, Newton RU, Chambers SK (2016) Improving psychosocial health in men with prostate cancer through an intervention that reinforces masculine values - exercise. Psychooncology 25:232-235. doi:10.1002/pon. 3867

10. Keating NL, O'Malley AJ, Freedland SJ, Smith MR (2013) Does comorbidity influence the risk of myocardial infarction or diabetes during androgen-deprivation therapy for prostate cancer? Eur Urol 64:159-166. doi:10.1016/j.eururo.2012.04.035

11. Levine GN, D'Amico AV, Berger P, Clark PE, Eckel RH, Keating NL, Milani RV, Sagalowsky AI, Smith MR, Zakai N, American Heart Association Council on Clinical Cardiology and Council on Epidemiology and Prevention, the American Cancer Society and the AUA (2010) Androgen-deprivation therapy in prostate cancer and cardiovascular risk: a science advisory from the American
Heart Association, American Cancer Society, and American Urological Association: endorsed by the American Society for Radiation Oncology. Circulation 121:833-840. doi:10.1161/ CIRCULATIONAHA.109.192695

12. Galvão DA, Spry NA, Taaffe DR, Newton RU, Stanley J, Shannon T, Rowling C, Prince R (2008) Changes in muscle, fat and bone mass after 36 weeks of maximal androgen blockade for prostate cancer. BJU Int 102:44 47. doi:10.1111/j.1464-410X.2008.07539.x

13. Galvão DA, Taaffe DR, Spry N, Joseph D, Turner D, Newton RU (2009) Reduced muscle strength and functional performance in men with prostate cancer undergoing androgen suppression: a comprehensive cross-sectional investigation. Prostate Cancer Prostatic Dis 12:198-203. doi:10.1038/pcan.2008.51

14. Smith MR, Lee H, Fallon MA, Nathan DM (2008) Adipocytokines, obesity, and insulin resistance during combined androgen blockade for prostate cancer. Urology 71:318-322. doi:10.1016/j.urology. 2007.08.035

15. Hamilton EJ, Ghasem-Zadeh A, Gianatti E, Lim-Joon D, Bolton D, Zebaze R, Seeman E, Zajac JD, Grossmann M (2010) Structural decay of bone microarchitecture in men with prostate cancer treated with androgen deprivation therapy. J Clin Endocrinol Metab 95: E456-E463. doi:10.1210/jc.2010-0902

16. Beebe-Dimmer JL, Cetin K, Shahinian V, Morgenstern H, Yee C, Schwartz KL, Acquavella J (2012) Timing of androgen deprivation therapy use and fracture risk among elderly men with prostate cancer in the United States. Pharmacoepidemiol Drug Saf 21:70-78. doi:10.1002/pds. 2258

17. Storer TW, Miciek R, Travison TG (2012) Muscle function, physical performance and body composition changes in men with prostate cancer undergoing androgen deprivation therapy. Asian J Androl 14:204-221. doi:10.1038/aja.2011.104

18. Hasenoehrl T, Keilani M, Sedghi Komanadj T, Mickel M, Margreiter M, Marhold M, Crevenna R (2015) The effects of resistance exercise on physical performance and health-related quality of life in prostate cancer patients: a systematic review. Support Care Cancer 23:2479-2497. doi:10.1007/s00520-015-2782-X

19. Kumar S, Shelley M, Harrison C, Coles B, Wilt TJ, Mason MD (2006) Neo-adjuvant and adjuvant hormone therapy for localised and locally advanced prostate cancer. Cochrane Database Syst Rev CD006019. doi: 10.1002/14651858.CD006019.pub2

20. Higano CS (2012) Sexuality and intimacy after definitive treatment and subsequent androgen deprivation therapy for prostate cancer. $\mathrm{J}$ Clin Oncol 30:3720-3725. doi:10.1200/JCO.2012.41.8509

21. Harrington JM, Schwenke DC, Epstein DR, Bailey DE (2014) Androgen-deprivation therapy and metabolic syndrome in men with prostate cancer. Oncol Nurs Forum 41:21-29. doi:10.1188/ 14.ONF.21-29

22. Bolla M, de Reijke TM, Van Tienhoven G, den Bergh ACM V, Oddens J, Poortmans PMP, Gez E, Kil P, Akdas A, Soete G, Kariakine O, van der Steen-Banasik EM, Musat E, Piérart M, Mauer ME, Collette L, EORTC Radiation Oncology Group and Genito-Urinary Tract Cancer Group (2009) Duration of androgen suppression in the treatment of prostate cancer. N Engl J Med 360: 2516-2527. doi:10.1056/NEJMoa0810095

23. Hanks GE, Pajak TF, Porter A, Grignon D, Brereton H, Venkatesan V, Horwitz EM, Lawton C, Rosenthal SA, Sandler HM, Shipley WU, Radiation Therapy Oncology Group (2003) Phase III trial of longterm adjuvant androgen deprivation after neoadjuvant hormonal cytoreduction and radiotherapy in locally advanced carcinoma of the prostate: the Radiation Therapy Oncology Group Protocol 9202. J Clin Oncol 21:3972-3978. doi:10.1200/JCO.2003.11.023

24. Pilepich MV, Winter K, Lawton CA, Krisch RE, Wolkov HB, Movsas B, Hug EB, Asbell SO, Grignon D, Carroll PR (2005) Androgen suppression adjuvant to definitive radiotherapy in prostate carcinoma-long-term results of phase III RTOG 85-31. Urol Oncol Semin Orig Investig 23:462-463. doi:10.1016/j.urolonc.2005.08.015 
25. Wilke DR, Krahn M, Tomlinson G, Bezjak A, Rutledge R, Warde P (2010) Sex or survival: short-term versus long-term androgen deprivation in patients with locally advanced prostate cancer treated with radiotherapy. Cancer 116:1909-1917. doi:10.1002/cncr.24905

26. Braga-Basaria M, Muller DC, Carducci MA, Dobs AS, Basaria S (2006) Lipoprotein profile in men with prostate cancer undergoing androgen deprivation therapy. Int J Impot Res 18:494 498. doi:10. 1038/sj.ijir.3901471

27. Galvão DA, Taaffe DR, Spry N, Joseph D, Newton RU (2009) Cardiovascular and metabolic complications during androgen deprivation: exercise as a potential countermeasure. Prostate Cancer Prostatic Dis 12:233-240. doi:10.1038/pcan.2009.12

28. Dockery F, Bulpitt CJ, Agarwal S, Donaldson M, Rajkumar C (2003) Testosterone suppression in men with prostate cancer leads to an increase in arterial stiffness and hyperinsulinaemia. Clin Sci (Lond) 104:195-201. doi:10.1042/CS20020209

29. Collier A, Ghosh S, McGlynn B, Hollins G (2012) Prostate cancer, androgen deprivation therapy, obesity, the metabolic syndrome, type 2 diabetes, and cardiovascular disease. Am J Clin Oncol 35: 504-509. doi:10.1097/COC.0b013e318201a406

30. Saigal CS, Gore JL, Krupski TL, Hanley J, Schonlau M, Litwin MS (2007) Androgen deprivation therapy increases cardiovascular morbidity in men with prostate cancer. Cancer 110:1493-1500. doi:10. 1002/cncr.22933

31. Nguyen PL, Chen M-H, Beckman JA, Beard CJ, Martin NE, Choueiri TK, Hu JC, Hoffman KE, Dosoretz DE, Moran BJ, Salenius SA, Braccioforte MH, Kantoff PW, D'Amico AV, Ennis RD (2012) Influence of androgen deprivation therapy on all-cause mortality in men with high-risk prostate cancer and a history of congestive heart failure or myocardial infarction. Int $\mathrm{J}$ Radiat Oncol Biol Phys 82:1411-1416. doi:10.1016/j.ijrobp.2011.04.067

32. Shahinian VB, Kuo Y-F, Freeman JL, Goodwin JS (2005) Risk of fracture after androgen deprivation for prostate cancer. N Engl $\mathrm{J}$ Med 352:154-164. doi:10.1056/NEJMoa041943

33. D'Amico AV, Denham JW, Crook J, Chen MH, Goldhaber SZ, Lamb DS, Joseph D, Tai KH, Malone S, Ludgate C, Steigler A, Kantoff PW (2007) Influence of androgen suppression therapy for prostate cancer on the frequency and timing of fatal myocardial infarctions. J Clin Oncol 25:2420-2425. doi:10.1200/JCO.2006.09.3369

34. Strasser B, Steindorf K, Wiskemann J, Ulrich CM (2013) Impact of resistance training in cancer survivors: a meta-analysis. Med Sci Sports Exerc 45:2080-2090. doi:10.1249/MSS. 0b013e31829a3b63

35. Lemes IR, Ferreira PH, Linares SN, Machado AF, Pastre CM, Netto JJ (2016) Resistance training reduces systolic blood pressure in metabolic syndrome: a systematic review and meta-analysis of randomised controlled trials. Br J Sports Med 50:1-6. doi:10. 1136/bjsports-2015-094715

36. Ricci-Vitor AL, Bonfim R, Fosco LC, Bertolini GN, Ramos EMC, Ramos D, Pastre CM, Godoy M, Vanderlei LCM (2013) Influence of the resistance training on heart rate variability, functional capacity and muscle strength in the chronic obstructive pulmonary disease. Eur J Phys Rehabil Med 49:793-801

37. Smith MR (2003) Changes in body composition during hormonal therapy for prostate cancer. Clin Prostate Cancer 2:18-21

38. Strasser B, Arvandi M, Siebert U (2012) Resistance training, visceral obesity and inflammatory response: a review of the evidence. Obes Rev 13:578-591. doi:10.1111/j.1467-789X.2012.00988.x

39. Bourke L, Doll H, Crank H, Daley A, Rosario D, Saxton JM (2011) Lifestyle intervention in men with advanced prostate cancer receiving androgen suppression therapy: a feasibility study. Cancer Epidemiol Biomark Prev 20:647-657. doi:10.1158/1055-9965.EPI-10-1143

40. Bourke L, Gilbert S, Hooper R, Steed LA, Joshi M, Catto JWF, Saxton JM, Rosario DJ (2014) Lifestyle changes for improving disease-specific quality of life in sedentary men on long-term androgen-deprivation therapy for advanced prostate cancer: a randomised controlled trial. Eur Urol 65:865-872. doi:10.1016/j. eururo.2013.09.040

41. Cormie P, Newton RU, Spry N, Joseph D, Taaffe DR, Galvão DA (2013) Safety and efficacy of resistance exercise in prostate cancer patients with bone metastases. Prostate Cancer Prostatic Dis 16: 328-335. doi:10.1038/pcan.2013.22

42. Cormie P, Galvão DA, Spry N, Joseph D, Chee R, Taaffe DR, Chambers SK, Newton RU (2015) Can supervised exercise prevent treatment toxicity in patients with prostate cancer initiating androgen-deprivation therapy: a randomised controlled trial. BJU Int 115:256-266. doi:10.1111/bju.12646

43. Galvão DA, Nosaka K, Taffee DR, Spry N, Kristjanson LJ, McGuigan MR, Suzuki K, Yamaya K, Newton RU (2006) Resistance training and reduction of treatment side effects in prostate cancer patients. Med Sci Sports Exerc 38:2045-2052. doi:10. 1249/01.mss.0000233803.48691.8b

44. Galvão DA, Taaffe DR, Spry N, Joseph D, Newton RU (2010) Combined resistance and aerobic exercise program reverses muscle loss in men undergoing androgen suppression therapy for prostate cancer without bone metastases: a randomized controlled trial. J Clin Oncol 28:340-347. doi:10.1200/JCO.2009.23.2488

45. Galvão DA, Spry N, Denham J, Taaffe DR, Cormie P, Joseph D, Lamb DS, Chambers SK, Newton RU (2014) A multicentre yearlong randomised controlled trial of exercise training targeting physical functioning in men with prostate cancer previously treated with androgen suppression and radiation from TROG 03.04 radar. Eur Urol 65:856-864. doi:10.1016/j.eururo.2013.09.041

46. Hanson ED, Sheaff AK, Sood S, Ma L, Francis JD, Goldberg AP, Hurley BF (2013) Strength training induces muscle hypertrophy and functional gains in black prostate cancer patients despite androgen deprivation therapy. J Gerontol Ser A Biol Sci Med Sci 68:490 498. doi:10.1093/gerona/gls206

47. Mina DS, Alibhai SMH, Matthew AG, Guglietti CL, Pirbaglou M, Trachtenberg J, Ritvo P (2013) A randomized trial of aerobic versus resistance exercise in prostate cancer survivors. J Aging Phys Act 21:455-478

48. Park SW, Kim TN, Nam JK, Ha HK, Shin DG, Lee W, Kim MS, Chung MK (2012) Recovery of overall exercise ability, quality of life, and continence after 12-week combined exercise intervention in elderly patients who underwent radical prostatectomy: a randomized controlled study. Urology 80:299-305. doi:10.1016/j.urology. 2011.12.060

49. Segal RJ (2003) Resistance exercise in men receiving androgen deprivation therapy for prostate cancer. J Clin Oncol 21:16531659. doi:10.1200/JCO.2003.09.534

50. Segal RJ, Reid RD, Courneya KS, Sigal RJ, Kenny GP, Prud'Homme DG, Malone SC, Wells GA, Scott CG, Slovinec D'Angelo ME (2009) Randomized controlled trial of resistance or aerobic exercise in men receiving radiation therapy for prostate cancer. J Clin Oncol 27:344-351. doi:10.1200/JCO.2007.15.4963

51. Winters-Stone MK, Dobek CJ, Bennett AJ, Maddalozzo FG, Ryan WC, Beer MT (2014) Skeletal response to resistance and impact training in prostate cancer survivors. Med Sci Sports Exerc 46: 1482-1488. doi:10.1249/MSS.0000000000000265

52. Livingston PM, Craike MJ, Salmon J, Courneya KS, Gaskin CJ, Fraser SF, Mohebbi M, Broadbent S, Botti M, Kent B (2015) Effects of a clinician referral and exercise program for men who have completed active treatment for prostate cancer: a multicenter cluster randomized controlled trial (ENGAGE). Cancer 121:26462654. doi: $10.1002 / \mathrm{cncr} .29385$

53. Nilsen TS, Raastad T, Skovlund E, Courneya KS, Langberg CW, Lilleby W, Fosså SD, Thorsen L (2015) Effects of strength training on body composition, physical functioning, and quality of life in prostate cancer patients during androgen deprivation therapy. Acta Oncol (Madr) 54:1805-1813. doi:10.3109/0284186X.2015. 1037008 
54. Winters-Stone KM, Lyons KS, Dobek J, Dieckmann NF, Bennett JA, Nail L, Beer TM (2016) Benefits of partnered strength training for prostate cancer survivors and spouses: results from a randomized controlled trial of the Exercising Together project. J Cancer Surviv 10:633-644 1-12. doi:10.1007/s11764-015-0509-0

55. Hojan K, Kwiatkowska-Borowczyk E, Leporowska E, Gorecki M, Ozga-Majchrzak O, Milecki TMP (2016) Physical exercise for functional capacity, blood immune function, fatigue and quality of life in high-risk prostate cancer patients during radiotherapy. A prospective, randomised clinical study. Eur J Phys Rehabil Med 52:489-501

56. Alberga AS, Segal RJ, Reid RD, Scott CG, Sigal RJ, Khandwala F, Jaffey J, Wells GA, Kenny GP (2012) Age and androgen-deprivation therapy on exercise outcomes in men with prostate cancer. Support Care Cancer 20:971-981. doi:10.1007/s00520-011-1169-x

57. Buffart LM, Galvão DA, Chinapaw MJ, Brug J, Taaffe DR, Spry N, Joseph D, Newton RU (2014) Mediators of the resistance and aerobic exercise intervention effect on physical and general health in men undergoing androgen deprivation therapy for prostate cancer. Cancer 120:294-301. doi:10.1002/cncr.28396

58. Cormie P, Newton RU, Taaffe DR, Spry N, Joseph D, Akhlil Hamid M, Galvão DA (2013) Exercise maintains sexual activity in men undergoing androgen suppression for prostate cancer: a randomized controlled trial. Prostate Cancer Prostatic Dis 16:170-175. doi:10. 1038/pcan.2012.52

59. Courneya KS, Segal RJ, Reid RD, Jones LW, Malone SC, Venner PM, Parliament MB, Scott CG, Quinney HA, Wells GA (2004) Three independent factors predicted adherence in a randomized controlled trial of resistance exercise training among prostate cancer survivors. J Clin Epidemiol 57:571-579. doi:10.1016/j.jclinepi.2003.11.010

60. Galvão DA, Nosaka K, Taaffe DR, Peake J, Spry N, Suzuki K, Yamaya K, McGuigan MR, Kristjanson LJ, Newton RU (2008) Endocrine and immune responses to resistance training in prostate cancer patients. Prostate Cancer Prostatic Dis 11:160-165. doi:10. 1038/sj.pcan.4500991

61. Galvão DA, Taaffe DR, Spry N, Joseph D, Newton RU (2011) Acute versus chronic exposure to androgen suppression for prostate cancer: impact on the exercise response. J Urol 186:1291-1297. doi:10.1016/j.juro.2011.05.055

62. Mina DS, Connor MK, Alibhai SMH, Toren P, Guglietti C, Matthew AG, Trachtenberg J, Ritvo P (2013) Exercise effects on adipokines and the IGF axis in men with prostate cancer treated with androgen deprivation: a randomized study. Can Urol Assoc J 7:E692-E698. doi:10.5489/cuaj.235

63. Winters-Stone KM, Dobek JC, Bennett JA, Dieckmann NF, Maddalozzo GF, Ryan CW, Beer TM (2014) Resistance training reduces disability in prostate cancer survivors on androgen deprivation therapy: evidence from a randomized controlled trial. Arch Phys Med Rehabil 96:7-14. doi:10.1016/j.apmr.2014.08.010

64. Gaskin CJ, Fraser SF, Owen PJ, Craike M, Orellana L, Livingston PM (2016) Fitness outcomes from a randomised controlled trial of exercise training for men with prostate cancer: the ENGAGE study. J Cancer Surviv. doi:10.1007/s11764-016-0543-6

65. Nilsen TS, Thorsen L, Fosså SD, Wiig M, Kirkegaard C, Skovlund E, Benestad HB, Raastad T (2015) Effects of strength training on muscle cellular outcomes in prostate cancer patients on androgen deprivation therapy. Scand J Med Sci Sports 26:1026-1035. doi:10. $1111 /$ sms. 12543

66. Nilsen TS, Thorsen L, Kirkegaard C, Ugelstad I, Fosså SD, Raastad $\mathrm{T}$ (2016) The effect of strength training on muscle cellular stress in prostate cancer patients on ADT. Endocr Connect 5:74-82. doi:10. 1530/EC-15-0120

67. Buffart LM, Newton RU, Chinapaw MJ, Taaffe DR, Spry NA, Denham JW, Joseph DJ, Lamb DS, Brug J, Galvao DA (2015) The effect, moderators, and mediators of resistance and aerobic exercise on health-related quality of life in older long-term survivors of prostate cancer. Cancer 121:2821-2830. doi:10.1002/cncr.29406

68. Gilbert SE, Tew GA, Fairhurst C, Bourke L, Saxton JM, Winter EM, Rosario DJ (2016) Effects of a lifestyle intervention on endothelial function in men on long-term androgen deprivation therapy for prostate cancer. Br J Cancer 114:401-408. doi:10.1038/bjc. 2015.479

69. Lyons KS, Winters-Stone KM, Bennett JA, Beer TM (2016) The effects of partnered exercise on physical intimacy in couples coping with prostate cancer. Health Psychol 35:509-513. doi:10.1037/ hea0000287

70. Winters-Stone KM, Dieckmann N, Maddalozzo GF, Bennett JA, Ryan CW, Beer TM (2015) Resistance exercise reduces body fat and insulin during androgen-deprivation therapy for prostate cancer. Oncol Nurs Forum 42:348-356. doi:10.1188/15.ONF.348-356

71. Gonnermann A, Framke T, Großhennig A, Koch A (2015) No solution yet for combining two independent studies in the presence of heterogeneity. Stat Med 34:2476-2480. doi:10.1002/sim.6473

72. Viechtbauer W (2010) Conducting meta-analyses in R with the metafor package. J Stat Softw 36:1-48. doi:10.1103/PhysRevB.91.121108

73. Cormie P, Pumpa K, Galvão DA, Turner E, Spry N, Saunders C, Zissiadis Y, Newton RU (2013) Is it safe and efficacious for women with lymphedema secondary to breast cancer to lift heavy weights during exercise: a randomised controlled trial. J Cancer Surviv 7: 413-424. doi:10.1007/s11764-013-0284-8

74. Muehlbauer T, Besemer C, Wehrle A, Gollhofer A, Granacher U (2012) Relationship between strength, power and balance performance in seniors. Gerontology 58:504-512. doi:10.1159/000341614

75. Beauchamp MK, Jette AM, Ward RE, Kurlinski LA, Kiely D, Latham NK, Bean JF (2015) Predictive validity and responsiveness of patient-reported and performance-based measures of function in the Boston RISE Study. J Gerontol Ser A Biol Sci Med Sci 70:616622. doi:10.1093/gerona/glu227

76. Kwon S, Perera S, Pahor M, Katula JA, King AC, Groessl EJ, Studenski SA (2009) What is a meaningful change in physical performance? Findings from a clinical trial in older adults (The LIFE-P study). J Nutr Heal Aging 13:538-544. doi:10.1007/ s12603-009-0104-Z

77. Chipperfield K, Fletcher J, Millar J, Brooker J, Smith R, Frydenberg M, Burney S (2013) Predictors of depression, anxiety and quality of life in patients with prostate cancer receiving androgen deprivation therapy. Psychooncology 22:2169-2176. doi:10. 1002/pon.3269

78. Gardner JR, Livingston PM, Fraser SF (2014) Effects of exercise on treatment-related adverse effects for patients with prostate cancer receiving androgen-deprivation therapy: a systematic review. J Clin Oncol 32:335-346. doi:10.1200/JCO.2013.49.5523

79. Weaver KE, Forsythe LP, Reeve BB, Alfano CM, Rodriguez JL, Sabatino SA, Hawkins NA, Rowland JH (2012) Mental and physical health-related quality of life among U.S. cancer survivors: population estimates from the 2010 National Health Interview Survey. Cancer Epidemiol Biomark Prev 21:2108-2117. doi:10.1158/10559965.EPI-12-0740

80. Silver J, Baima J, Mayer R (2013) Impairment-driven cancer rehabilitation. Cancer J Clin 63:295-317. doi:10.3322/caac.21186

81. Hasenoehrl T, Wessner B, Tschan H, Vidotto C, Crevenna R, Csapo R (2016) Eccentric resistance training intensity may affect the severity of exercise induced muscle damage. J Sports Med Phys Fitness

82. Ahmadi H, Daneshmand S (2013) Androgen deprivation therapy: evidence-based management of side effects. BJU Int 111:543-548. doi:10.1111/j.1464-410X.2012.11774.x

83. Alibhai SMH, Breunis H, Timilshina N, Johnston C, Tomlinson G, Tannock I, Krahn M, Fleshner NE, Warde P, Canning SD, Klotz L, Naglie G (2010) Impact of androgen-deprivation therapy on physical function and quality of life in men with nonmetastatic prostate cancer. J Clin Oncol 28:5038-5045. doi:10.1200/JCO.2010.29.8091 